\title{
HEALTH INEQUALITY ON LABOR MARKET: EXPLORING HEALTH-RELATED EMPLOYMENT TRANSITIONS AMONG KOREAN YOUNG ADULTS
}

\section{Ekaterina Baldina ${ }^{1}$}

Abstract

This study aims to evaluate relationships between employees' subjective and mental health and non-regular employment. I use three-wave (2012, 2015, and 2018) from the Korean Youth Panel data to access relationships between health indicators and non-regular employment. I also explore gender differences to access if relationships between health and employment are different for the two sexes. I utilized the random-effects model to estimate the association between health indicators and non-regular employment across three waves. I found that mental health indicators rather than subjective health affect one's odds of attending a temporary job. Also, the transition or maintenance of temporary positions showed that mental health indicators were associated with the transition from regular to a temporary job but were not associated with the maintenance of temporary positions. Additional analysis showed men were more likely to attend a temporary job if they had suicidal thoughts, while women were more susceptible to daily stress, despair, and suicidal thoughts altogether. I discuss the implications of this study for research and policy on non-regular employment's influence on youth's health.

\footnotetext{
1 Yonsei University, Graduate School, Department of Sociology. E-mail: katebaldina@gmail.com
} 


\section{INTRODUCTION}

\section{Precarious employment and youth}

The 1997 financial crisis in South Korea brought neoliberalism and labor market flexibility, which led to important structural changes in employment patterns (Lee, 2001; Kim, 2003). Also, one important factor that distinct South Korean neoliberalisation from Western one is the absence of a safety net with minimal pension, retirement allowances, or employment-based medical insurance for nonstandard workers (Kim, 2003). Considering this background, thorough research is necessary to access the relationships between nonstandard employment and the health of workers.

At the beginning of the presidency term, President Moon claimed that he plans to transfer non-regular workers to regular positions by the end of his presidency. However, this policy is limited to people who are older than 60 years old and school non-regular workers. It is true that these categories of the population are vulnerable and need the state's attention. However, a vast majority of the youth population, who in the future will drive the Korean economy, remained at the blind spot. Among 15-24 years, old people 50\% are non-regular workers, and this tendency keeps growing (한국노동연구원, 통계청). Also of more than $50 \%$ of them are alienated from the benefits of social welfare like health insurance, state pension, and employment insurance. This situation inevitably raises the question about the health condition of non-regular workers. Moreover, considering the increment in non-regular workers' proportion, we can suppose that the non-regular employment is a rather long-term phenomenon. On the other hand, the person who lacks various health insurance benefits, might have weaker health, and therefore be more likely to often job changes and have a lower probability to settle a regular position.

One of the greatest effects of job instability among youth might be disrupted path in the transition to adulthood. Traditionally, the transition to adulthood means successful completion of the five life events: graduation, starting a full-time job, leaving the home of origin, marriage or forming a union, and become a parent (Shanahan, 2000). Although the sequence of these events can differ from individual to individual and from culture to culture, an important thing to notice is that transition to adulthood assumes that an individual becomes independent and acquire the ability to take responsibility for itself. However, unstable job conditions make it often impossible for young people to fulfill their plans for the establishment of the family or their personal goals. Especially in Korea, there are even special terms for this phenomenon which is known as the N-po generation, people who gave up numerous things due to economic instability and social pressure.

\section{Gender differences}

Gender differences in the labor market are well-documented. Women are more likely to be in temporary contracts than men (C Young, 2010). Considering such jobs, women are more likely to have worse conditions, a lower payment, and fewer welfare benefits (Cranford et al., 2003). Since women have more structural disadvantages not only in terms of the propensity 
of being employed in a temporary job, but also have worse conditions than men, it is plausible to suggest that women might have more health disadvantages than men about employment in a temporary job. Very few studies examined differences by gender (Ferrie et al., 1998), while most studies merely adjusted analysis for sex (Benavides et al., 2000; Rodriguez, 2002). Available for review studies claims that precarious employment detrimental for both men and women (Ferrie et al., 2002). However, some factors are indicating that precarious employment can damage women's health more than men's (Menéndez et al., 2007). These are the gender division of labor and the "breadwinner" ideology that channel women into unemployment and part-time jobs (Franco and Winqvist, 2002); gender occupational segregation that forces women into a restricted range of "female occupations" (Aronsson et al., 2002); women tend to combine work with household responsibilities, which weakens women's position in the labor market (Heilman, 2012). As a result, there are possible differences in how health affects the propensity of attending a temporary job.

I aim to evaluate the probability of attending temporary job due to health problems among sample of Korean young adults (18 34 y.o.). First, I will evaluate change in transition from temporary to regular employment and vice versa. Then, using multivariate regression analysis I will access which of the health characteristic is associated with transition or maintenance of temporary job. Third, I will evaluate gender differences in associations between health and job types. Last, I will elaborate on possible mechanisms and directions for future research as well implication for policymakers.

\section{METHODS}

\section{Data}

Using longitudinal data from the Korean Panel Survey of Young Adults (청년패널조사) and panel analysis models, I ask two questions: (1) Do bad health condition increase the likelihood of being in a precarious job? (2) How do their respective effects vary with previous attendance of precarious jobs? A 3-wave $(2009,2012$, and 2018) was used to answer these questions.

\section{Participants}

Of the 10,206 participants at the baseline, 2,080 respondents participated in wave 6 (2012), wave 9 (2015), and wave 12 (2018) and were employed. The average age of respondents was 28.4 years old and ranged from 19 to 34 . Around $80 \%(1,600)$ were college graduates. The year income median in 2012 (wave 6) was 2,300,000 million won, which is highly skewed to the right. Around $11 \%$ of the respondents evaluated their health in the 2012 year (wave 6) as average and lower.

\section{Measures}

I use waves 6 (2012) and 9 (2015) and 12 (2018) to access relationships between precarious work and health status. Health status was measured during waves 6,9 , and 12 . I use self-rated health, measured on a 5 -point Likert scale ( $1=$ Very healthy, $5=$ Very unhealthy). 
I also use the measure for daily stress. Respondents were asked if they are experiencing stress in daily life. Responses ranged from 1 (I experience a lot of stress) to 4 (I do not experience stress at all).

Despair was measured with a 1-item question. Respondents were asked if they experienced despair during the last two weeks. Responses were coded as 1 for "Yes" and 0 for "No".

Suicidal ideation was coded as 1 if the respondent had suicidal thoughts during the last 1 year, and 0 if he or she had not.

Non-regular employment status was measured as whether individuals were in a permanent or temporary position.

I control for age, mother's education, income, one's education level, marital status, weekly work hours, and size of a company. To control for the nonlinear effect of age, I introduce the quadratic term into the equation. Marital status was measured as a binary variable, coded as 1 for being married and 0 for being unmarried, widowed, or divorced. Income was introduced in a long term due to skewness. Mother's education was coded as 1 if the mother graduated from college and higher, and 0 if she graduated from high school and lower. The weekly work hours measure was introduced as a continuous variable with a range from 4 to 84 . Company size was coded as a binary variable for 1 if the company had 50 and more employees, and 0 if less than 49.

\section{Analytical plan}

Descriptive analysis of the main predictors and dependent variables was performed for each wave (Table 1). I also accessed the difference between men and women using the Student t-test. Transition and maintenance of job position analysis were conducted descriptively across all waves (Table 2 ).

First, I utilize random effects panel models to estimate the likelihood of being at a precarious job among Korean Young adults. Additionally, I conducted separate analyses for samples who previously attended precarious jobs and those who did not explore the effect of health on transition and maintained a position in the precarious job. Data analysis was performed in Stata 16.0 (Stata Corp., College Station, TX).

\section{RESULTS}

The descriptive characteristics of the sample are presented in Table 1. At the first wave (2012) about $11.1 \%$ of the sample was at non-regular employment. However, this proportion decreased to $5.9 \%$ by the year 2018 , suggesting that over time a substantial proportion of non-regular workers among young adults proceed for stable and regular employment. As for health indicators, average self-rated health slightly increased over time, indicating that selfrated perception of health is becoming worse among young adults over time (item is reverse coded). An only a small proportion of the population, less than $3 \%$, felt despair and had suicidal ideation, and the trend was quite stable over time. Daily stress (item is reverse coded) also shows degradation over time, suggesting that young adults feel more stressed as they proceed to adulthood. Table 2 shows descriptive statistics of transitions between different 
types of employment. Almost $40 \%$ of the sample ended up in stable employment, while also $60 \%$ just stayed in temporary jobs. This trend probably reflects long-term changes in the job market and the prevalence of temporary employment due to economic restructuring.

Figure 1 presents results from the random-effects logistic regression model on the transition from stable employment to temporary one due to one of the health characteristics. All models were run separately for each independent health variable. Except for self-rated health, all mental health-related characteristics significantly predicted odds of attending a temporary position in the next wave. Especially odds were high for suicidal thoughts $(O R=3.12$, $p<0.005)$ which can be an important sign for policy-makers.

Table 1. Descriptive characteristics for respondents: Youth Panel, 2012, 2015, and 2018.

$\begin{array}{llc} & & \mathbf{N}=\mathbf{2 , 0 8 0} \\ \text { Employment (2012) } & \text { Regular } & 1,850(88.9 \%) \\ & \text { Non-regular } & 230(11.1 \%) \\ \text { Employment (2015) } & \text { Regular } & 1,923(92.5 \%) \\ & \text { Non-regular } & 157(7.5 \%) \\ \text { Employment (2018) } & \text { Regular } & 1,958(94.1 \%) \\ & \text { Non-regular } & 122(5.9 \%) \\ \text { Self-rated health (2012) } & & 1.9(0.6) \\ \text { Self-rated health (2015) } & 1.9(0.6) \\ \text { Self-rated health (2018) } & 2.1(0.6) \\ \text { Suicidal ideation (2012) } & 26(1.3 \%) \\ \text { Suicidal ideation (2015) } & 16(0.8 \%) \\ \text { Suicidal ideation (2018) } & 31(1.5 \%) \\ \text { Despair (2012) } & & 49(2.4 \%) \\ \text { Despair (2015) } & 28(1.3 \%) \\ \text { Despair (2018) } & 41(2.0 \%) \\ \text { Stress (2012) } & 2.7(0.6) \\ \text { Stress (2015) } & 2.8(0.6) \\ \text { Stress (2018) } & & 2.9(0.5)\end{array}$

Next, I analyzed the transition from non-temporary jobs to temporary and the maintenance of temporary jobs. Surprisingly, only estimates in the transition model were significant: bad health predicted transition from a stable job to a temporary one. Especially, again suicidal thoughts had higher odds $(O R=4.21, p<0.05)$, following by daily stress $(O R=1.39, p<0.05)$.

Last, I investigated gender differences in the association between health characteristics and temporary job attendance. First, males who feel suicidal thoughts almost seven times more likely to attend a temporary job $(O R=6.95, p<0.05)$. However, women with suicidal thoughts also were more likely to opt for a temporary position $(O R=5.11, p<0.01)$, while other mental health issues also took place. Women who felt despair were three times likely and those who experienced stress were 0.57 times likely to attend a temporary job.

Table 2. The transition of employment status over time $(n=7,582)$ 


\begin{tabular}{clccc}
\hline & & Employment status at T+1 & Total \\
\hline \multirow{2}{*}{ Employment status at $\mathbf{T}$} & Regular & Non-regular & \\
\cline { 2 - 5 } & Regular & $96.69 \%$ & $3.31 \%$ & $100 \%$ \\
\cline { 2 - 5 } & Non-regular & $61.34 \%$ & $38.66 \%$ & $100 \%$ \\
\hline \multirow{2}{*}{ Total } & $92.15 \%$ & $7.85 \%$ & $100 \%$
\end{tabular}

Figure 1. Odds Ratio of being at temporary employment due to health-risks

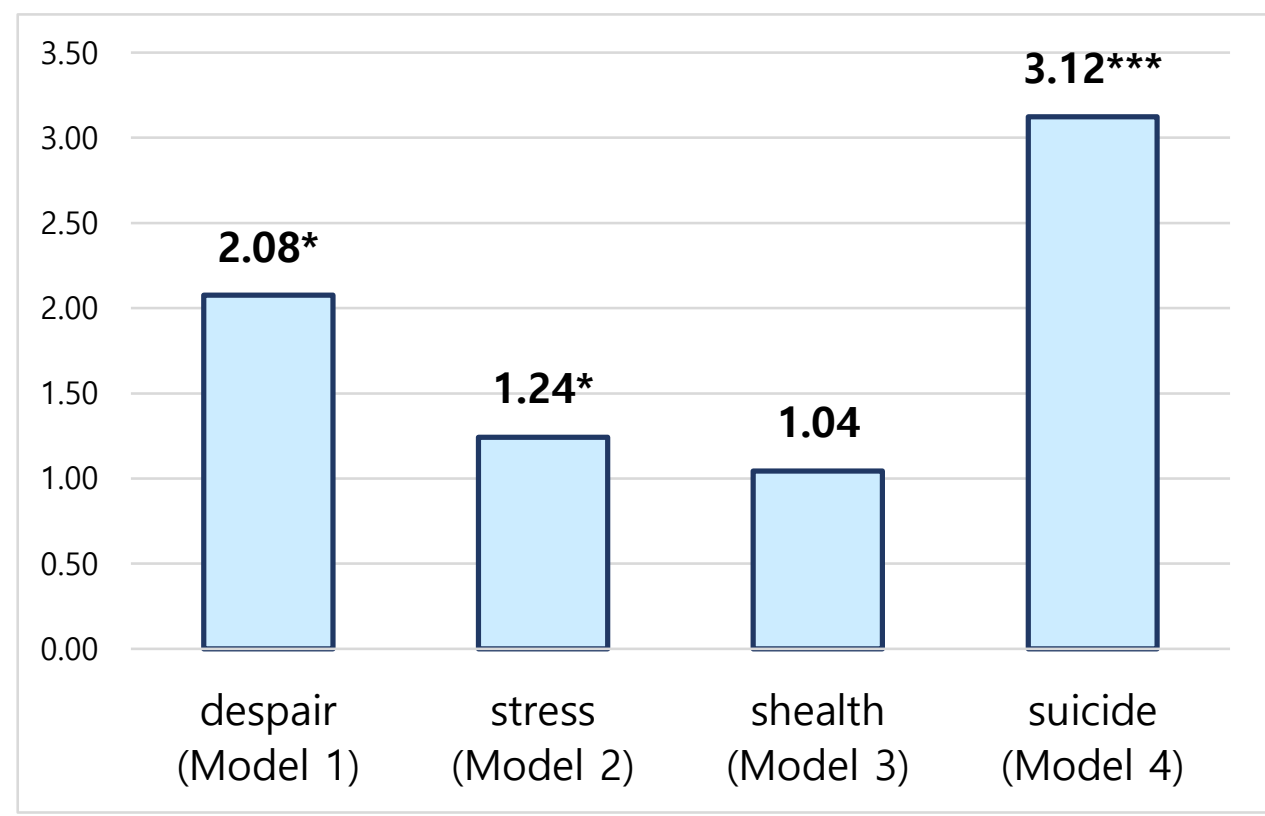

${ }^{*} \mathrm{p}<0.05,{ }^{* *} \mathrm{p}<0.01,{ }^{* * *} \mathrm{p}<0.005$

Each model controlled for age, gender, education marital status, log of income, mother's education, working hours and mother's education 
Figure 2. The odds ratio of maintaining temporary position (left) or transit from regular (right) to a temporary position due to health characteristics $(n=937)$

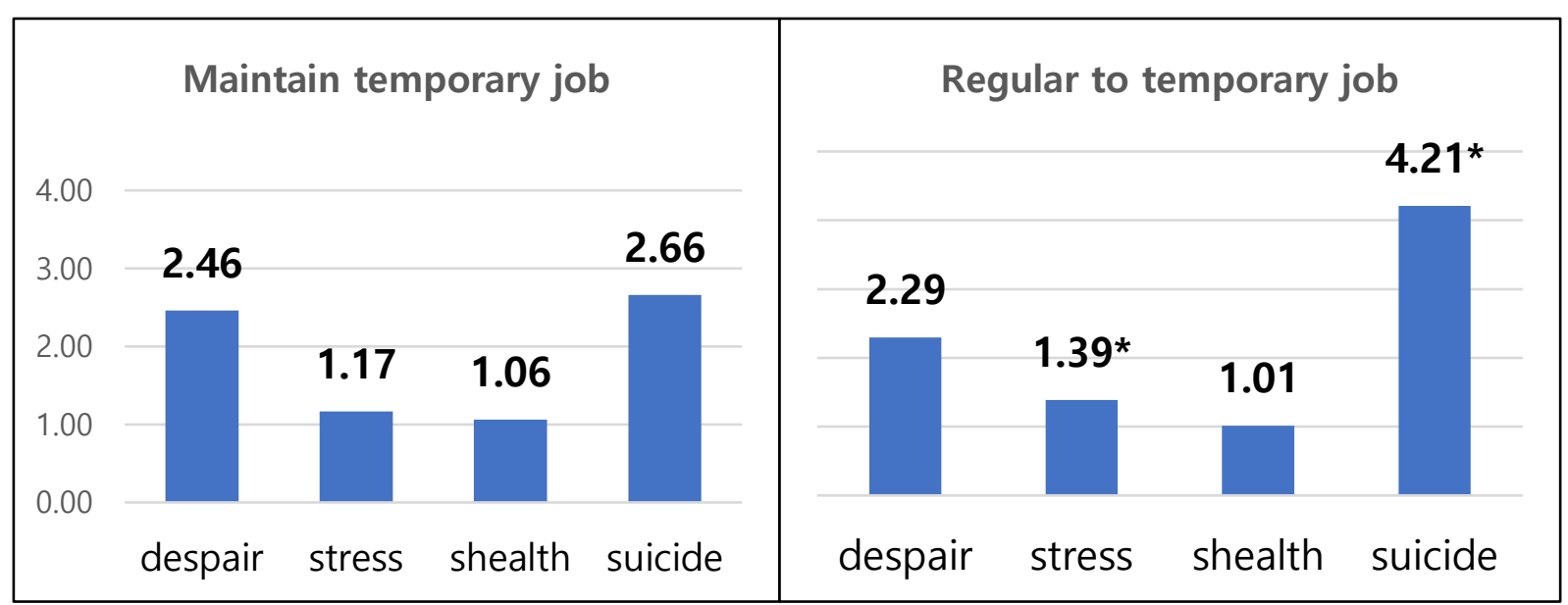

* $\mathrm{p}<0.05,{ }^{* *} \mathrm{p}<0.01,{ }^{* * *} \mathrm{p}<0.005$

Each model controlled for age, gender, education marital status, log of income, mother's education, working hours and mother's education

Figure 3. The odds ratio of transition to temporary employment due to health by gender.

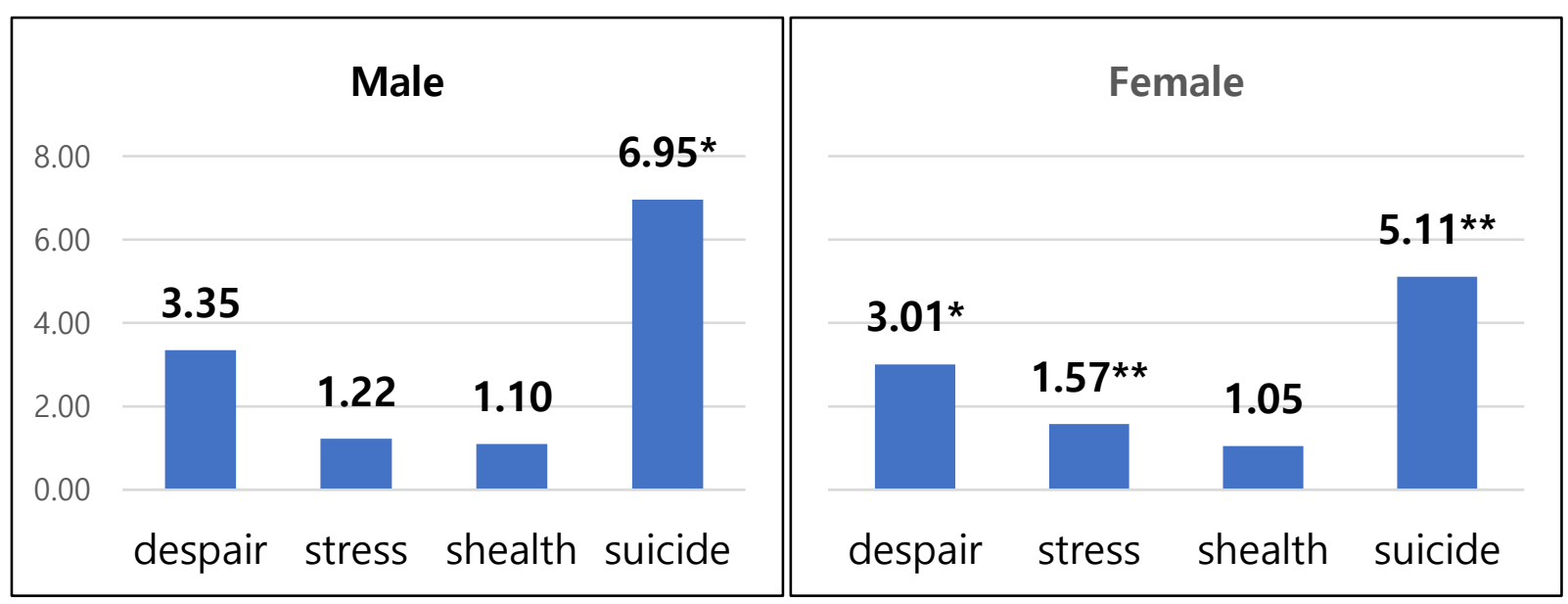

* $\mathrm{p}<0.05,{ }^{* *} \mathrm{p}<0.01, * * * \mathrm{p}<0.005$

Each model controlled for age, gender, education marital status, log of income, mother's education, working hours and mother's education 


\section{DISCUSSION}

I examined the effect of health on the transition to temporary employment among Korean young adult nationally representative samples. The analysis revealed that stress, despair, and suicidal thoughts are the factors associated with one's employment position. On the other hand, subjective health was not associated with the propensity of being a temporary job. Further analysis of the sub-group, who was previously at the non-temporary job, confirmed relationships between mental health characteristics and transition to a temporary job in the next wave. On the other hand, health characteristics were not significantly associated with the propensity of staying in a temporary position among those who already had been in one. Women showed more propensity for moving to a temporary job if they had suicidal thoughts, stress, and despair, while for men suicidal thoughts were the sole predictor of proceeding to a temporary position.

Most previous research focused on the exploration of causal relationships between temporary jobs and health. However, less research was concerned with the reverse causal model, when health disparities can produce labor market disparity. Personal health and wellbeing affect productivity (Kahn and Langlieb, 2003), which helps to get promotions and increase income (Case, 2002). Therefore, people with weak health and lower well-being have an initial disadvantage in the labor market, which can prevent them to get an advanced workplace. Giving that more young people these days experience mental health problem and the problem of unemployment and tough condition for finding a decent job, might affect individual's mental health and contribute to ending up in temporary position, which produces a vicious cycle between mental health problems and unstable employment (장재윤 외, 2004). In other words, I argue that mental health is not a problem of an individual, but might be the consequence of the macro phenomena like that of the 1998 economic crisis or 2008 economic crisis that dramatically affected peoples wellbeing, including mental health (Haw et al., 2015; Hong et al., 2011; Chang et al., 2009). Many studies reported an increase in suicidal behavior, depression, and other mental issues during and a long time after the 2008 economic crisis occurred (Hong, Knapp and McGuire, 2011) Therefore, it is important to (1) access reciprocal relationships between mental health and unstable employment and (2) explore macro issues that affect young adults mental health and prevent them from staying in regular jobs.

Another issue is who opt for or stay in the precarious job. The analysis showed that mental health characteristics affected the transition from non-temporary position to temporary, rather than contributed to maintaining in a temporary job. Regular positions might be highly stressful and not all people get promotions and remain in the firm (Stansfeld and Candy, 2006). Some people are to quit and look for another workplace. While the reasons could be different, weak health and high mental distress might be one of the factors that select people out of regular jobs. Future research should investigate possible mechanisms that contribute to the transition from a regular job to other kinds of employment and consider health as one of the important factors.

Analysis of gender differences did not show salient results, although women who experienced daily stress were more likely to opt for a temporary job. Generally, women experience a higher level of stress in academic settings (Backović et al., 2012), workplace stress (Herrero et al., 2012), experience burnout, and emotional exhaustion (Purvanova and Muros, 2010). Since women are more likely to also experience work-family conflict (Duxbury 
and Higgins, 1991), stressed women are more likely to opt for temporary and non-regular jobs to relieve their conflicts. Further research is needed about gender differences in employment type change, mental health, and work-life balance.

My research has several limitations. First, due to the nature of the dependent variable and small change from individual to individual in work status, I was unable to apply the fixed-effect model, which could help me to assess results while controlling for unobserved individual characteristics. Second, more elaborate definitions and more different variables, representing non-regular jobs are needed to analyze different labor market outcomes. Third, I did not access more long sequence of transition from and to a temporary position which might be important. For example, one person might opt for a temporary position due to excessive stress on a previous job, but consequently to seek another stable position. The number of transitions also might be an important factor in mental health deterioration, which should be investigated.

In my paper, I tried to analyze which health factors produce labor market disparity and explore health characteristics that contribute to the transition and maintenance in the temporary workplace. Policymakers should take into account not only initial labor market conditions, but also consider workplace mental conditions, and initial mental health of newly graduated or just entered to labor market young adults.

\section{REFERENCES}

Aronsson, G., Gustafsson, K., and Dallner, M., 2002. "Work environment and health in different types of temporary jobs". "European journal of work and organizational psychology" 11, p.(151-175).

Backović, D. V., Ilić Živojinović, J., Maksimović, J., and Maksimović, M., 2012. "Gender differences in academic stress and burnout among medical students in final years of education". "Psychiatria Danubina" 24, p.(175-181).

Benavides, F. G., Benach, J., Diez-Roux, A. V., and Roman, C., 2000. "How do types of employment relate to health indicators? Findings from the Second European Survey on Working Conditions". "Journal of Epidemiology \& Community Health" 54, p.(494-501).

C Young, M., 2010. "Gender differences in precarious work settings". "relations industrielles/industrial relations" 65, p.(74-97).

Case, A., 2002. "Health, income, and economic development". Proceedings of the World Bank Conference on Development Economics, 2001/2002, p.(221-241).

Chang, S.-S., Gunnell, D., Sterne, J. A., Lu, T.-H., and Cheng, A. T., 2009. "Was the economic crisis 1997-1998 responsible for rising suicide rates in East/Southeast Asia? A time-trend analysis for Japan, Hong Kong, South Korea, Taiwan, Singapore, and Thailand". "Social science \& medicine" 68, p.(1322-1331).

Cranford, C., Vosko, L., and Zukewich, N., 2003. "The gender of precarious employment in Canada". "Relations industrielles/Industrial relations" 58, p.(454-482).

Duxbury, L. E., and Higgins, C. A., 1991. "Gender differences in work-family conflict". "Journal of applied psychology" 76, p.(60).

Ferrie, J. E., Shipley, M. J., Marmot, M. G., Stansfeld, S., and Smith, G. D., 1998. "The health effects of 
major organizational change and job insecurity". "Social science \& medicine" 46, p.(243-254).

Ferrie, J. E., Shipley, M. J., Stansfeld, S. A., and Marmot, M. G., 2002. "Effects of chronic job insecurity and change in job security on self-reported health, minor psychiatric morbidity, physiological measures, and health-related behaviors in British civil servants: the Whitehall II study". "Journal of Epidemiology \& Community Health" 56, p.(450-454).

Franco, A., and Winqvist, K., 2002. "At the margins of the labor market? Women and men in temporary jobs in Europe". "Statistics in focus" 13, p.(2002).

Haw, C., Hawton, K., Gunnell, D., and Platt, S., 2015. "Economic recession and suicidal behavior: Possible mechanisms and ameliorating factors". "International Journal of Social Psychiatry" 61, p.(73-81).

Heilman, M. E., 2012. "Gender stereotypes and workplace bias". "Research in organizational Behavior" 32, p.(113-135).

Herrero, S. G., Saldaña, M. Á. M., Rodriguez, J. G., and Ritzel, D. O., 2012. "Influence of task demands on occupational stress: gender differences". "Journal of Safety Research" 43, p.(365-374).

Hong, J., Knapp, M., and McGuire, A., 2011. "Income-related inequalities in the prevalence of depression and suicidal behavior: a 10-year trend following economic crisis". "World Psychiatry" 10 , p.(40).

Kahn, J. P., and Langlieb, A. M., 2003. Mental health and productivity in the workplace: A handbook for organizations and clinicians.Jossey-Bass,

Kim, Y., 2003. "The size and realities of contingent workers-Korea National Statistical Office; 'The result of economically active population add survey (2003.8)'". "Monthly Magazine for Labor and Society" 12, p.(72-91).

Lee, J. 2001. A study on neo-liberalistic restructuring and the change in South Korea. Dissertation, Korea University.

Menéndez, M., Benach, J., Muntaner, C., Amable, M., and O'Campo, P., 2007. "Is precarious employment more damaging to women's health than men's?". "Social Science \& Medicine" 64 , p.(776-781).

Purvanova, R. K., and Muros, J. P., 2010. "Gender differences in burnout: A meta-analysis". "Journal of vocational behavior" 77, p.(168-185).

Rodriguez, E., 2002. "Marginal employment and health in Britain and Germany: does unstable employment predict health?". "Social science \& medicine" 55, p.(963-979).

Stansfeld, S., and Candy, B., 2006. "Psychosocial work environment and mental health-a metaanalytic review". "Scandinavian journal of work, environment \& health" p.(443-462).

장재윤, 장은영, 김범성, 노연희, 이지영, 한지현, 2004. 「청년실업이 정신건강에 미치는 영향에 대

한 종단연구」. 한국심리학회지: 일반, 23호, p.(121-144). 